\title{
Chapter 4 \\ The Relationship Between Teacher \\ Professional Community and Participative \\ Decision-Making in Schools in 22 \\ European Countries
}

\author{
Catalina Lomos
}

\subsection{Introduction}

The literature on school effectiveness and school improvement highlights a positive relationship between professional community and participative decision-making in creating sustainable innovation and improvement (Hargreaves \& Fink, 2009; Harris, 2009; Smylie, Lazarus, \& Brownlee-Conyers, 1996; Wohlstetter, Smyer, \& Mohrman, 1994). Many authors, beginning with Little (1990) and Rosenholtz (1989), indicated that teachers' participation in decision-making builds upon teacher collaboration and that the interaction of these elements leads to positive change and better school performance (Harris, 2009). Moreover, Carpenter (2014) indicated that school improvement points to a focus on professional community practices as well as supportive and participative leadership.

Broad participation in decision-making across the school is believed to promote cooperation and student development via valuable exchange regarding curriculum and instruction. Smylie et al. (1996) see a relevant and positive relationship, especially between participation in decision-making and teacher collaboration for learning and development, in the form of professional community. The authors consider that participation in decision-making may affect relationships between teachers and organisational learning opportunities due to increased responsibility, greater perceived accountability, and mutual obligation to respect the decisions made together.

Considering the desideratum of school improvement when identifying what factors facilitate better teacher and student outcomes (Creemers, 1994), the positive relationship between teacher collaboration within professional communities and teacher/staff participation in decision-making becomes of higher interest. The question that arises is whether this study-specific positive relationship identified can be

C. Lomos $(\bowtie)$

Luxembourg Institute of Socio-Economic Research (LISER), Esch-sur-Alzette, Luxembourg

e-mail: Catalina.Lomos@liser.lu 
considered universal and can be found across countries and educational systems. Therefore, the present study aims to investigate the following research questions across 22 European countries:

1. What is the relationship between professional community and participation in decision-making in different European countries?

2. Which of the actors involved in decision-making are most indicative of higher perceived professional community practices in different European countries?

In order to answer these research questions, the relationship between the two concepts needs to be estimated and compared across countries. Many authors, such as Billiet (2003) or Boeve-de Pauw and van Petegem (2012), have indicated how distorted cross-cultural comparisons can be when cross-cultural non-equivalence is ignored; thus, testing for measurement invariance of the latent concepts of interest should be a precursor to all country comparisons. The present chapter will answer these questions by applying a test for measurement invariance of the professional community latent concept as a cross-validation of the classical, comparative approach and will then discuss the impact of such a test on results.

\subsection{Theoretical Section}

\subsubsection{Professional Community $(P C)$}

Professional Community (PC) is represented by the teachers' level of interaction and collaboration within a school; it has been empirically established as relevant to teachers' and students' work (e.g. Hofman, Hofman, \& Gray, 2015; Louis \& Kruse, 1995). The concept has been under theoretical scrutiny for the last three decades, with the agreement that teachers are part of a professional community when they agree on a common school vision, engage in reflective dialogue and collaborative practices, and feel responsible for school improvement and student learning (Lomos, Hofman, \& Bosker, 2012; Louis \& Marks, 1998).

Regarding these specific dimensions of PC, Kruse, Louis, and Bryk (1995), "designated five interconnected variables that describe what they called genuine professional communities in such a broad manner that they can be applied to diverse settings" (Toole \& Louis, 2002, p. 249). These five dimensions measuring the latent concept of professional community have been defined, based on Louis and Marks (1998) and other authors, as follows: Reflective Dialogue (RD) refers to the extent to which teachers discuss specific educational matters and share teaching activities with one another on a professional basis. Deprivatisation of Practice (DP) means that teachers monitor one another and their teaching activities for feedback purposes and are involved in observation of and feedback on their colleagues. Collaborative Activity (CA) is a temporal measure of the extent to which teachers engage in cooperative practices and design instructional programs and plans 
together. Shared sense of Purpose (SP) refers to the degree to which teachers agree with the school's mission and take part actively in operational and improvement activities. Collective focus or Responsibility for student learning (CR) and a collective responsibility for school operations and improvement in general indicate a mutual commitment to student learning and a feeling of responsibility for all students in the school. This definition of PC has also been the measure most frequently used to investigate the PC's quantitative relationship with participative decisionmaking (e.g. Louis \& Kruse, 1995; Louis \& Marks, 1998; Louis, Dretzke, \& Wahlstrom, 2010).

\subsubsection{Participative Decision-Making (PDM)}

The framework of participative decision-making as a theory of leadership practice has long been studied and has multiple applications in practice. Workers' involvement in the decisions of an organization has been investigated for its efficacy since 1924, as indicated by the comprehensive review of Lowin for the years between 1924 and 1968 (Conway, 1984). Regarding the involvement of educational personnel and the details of their participation, Conway (1984) characterizes their participation as "mandated versus voluntary", "formal versus informal", and "direct versus indirect". These dimensions differentiate the involvement of different actors, who could be involved in decision-making within schools. A few studies performed later, once school-based, decision-making measures had been implemented, such as Logan (1992) in the US state of Kentucky, listed principals, counsellors, academic and non-academic teachers and students as school personnel actively involved in decision-making.

When referring to participation in decision-making (PDM), specifically in educational organizations, Conway (1984) described the concept as an intersection of two major conceptual notions: decision-making and participation. Decision-making indicates a process, in which one or more actors determine a particular choice. Participation signifies "the extent to which subordinates, or other groups who are affected by the decisions, are consulted with, and involved in, the making of decisions" (Melcher, 1976, p. 12, in Conway, 1984).

Conway (1984) discusses the external perspective, which implies the participation of the broader community, and the internal perspective, which implies the participation of school-based actors. In many countries, including England (Earley \& Weindling, 2010), the school governors are expected to have an important nonactive leadership role in schools, more focused on "strategic direction, critical friendship and accountability" (p. 126), providing support and encouragement. The school counsellor has more of a supportive leadership role in facilitating the academic achievement of all students (Wingfield, Reese, \& West-Olantunji, 2010) and enabling a stronger sense of school community (Janson, Stone, \& Clark, 2009). Teacher participation can take the form of individual leadership roles for teachers or teacher advisory groups (Smylie et al., 1996). Students are also actors in 
participative decision-making, especially when decisions involve the instructional process and learning materials. Students would need to discuss topics and learning activities with one another and their teachers to be informed for such decisionmaking; this increases the likelihood of collaborative interactions (Conway, 1984). Significantly, teachers have been identified as the most important actors, either formally or informally involved in participative decision-making; as such, reform proposals have recommended the expansion of teachers' participation in leadership and decision-making tasks (Louis et al., 2010).

\subsubsection{The Relationship Between Professional Community and Participative Decision-Making}

After following schools implementing participative decision-making with different actors involved, many studies found it imperative for teachers to interact if any meaningful and consistent sharing of information was to occur (e.g. Louis et al., 2010; Smylie et al., 1996). Moreover, they found that participative decision-making promotes collaboration and can bring teachers together in school-wide discussions. This phenomenon could limit separatism and increase interaction between different types of teachers (e.g. academic or vocational), especially in secondary schools (Logan, 1992). These studies also found that schools move towards mutual understanding through participation in decision-making, thus facilitating PC (p. 43). For Spillane, Halverson, and Diamond (2004), PC can facilitate broader interactions within schools. The authors have also concluded that "the opportunity for dialogue contributes to breaking down the school's 'egg-carton' structure, creating new structures that support peer-communication and information-sharing, arrangements that in turn contribute to defining their leadership practice" (p. 27).

In conclusion, the relationship between professional community (PC) and actors of participative decision-making (PDM) has found to be significant and positive in different studies performed across varied educational systems (e.g. Carpenter, 2014; Lambert, 2003; Louis \& Marks, 1998; Logan, 1992; Louis et al., 2010; Morrisey, 2000; Purkey \& Smith, 1983; Smylie et al., 1996; Stoll \& Louis, 2007). These findings support our expectation that this relationship is positive; PC and PDM mutually and positively influence each other over time, and this interaction creates paths to educational improvement (Hallinger \& Heck, 1996; Pitner, 1988).

\subsubsection{The Specific National Educational Contexts}

Professional requirements to obtain a position as a teacher or a school leader vary widely across Europe. The 2013 report (Eurydice, 2013, Fig. F5, p. 118) describes the characteristics of participative decision-making, as well as other data, from 
2011-2012 (relevant period for the present study) from pre-primary to upper secondary education in the studied countries.

From this report, we see that some countries share characteristics of participative decision-making; however, no typology of countries has yet been established or tested in this regard.

In most of the countries, participation is formal, mandated, and direct (Conway, 1984). More specifically, in countries, such as Belgium (Flanders) (BFL), Cyprus (CYP), the Czech Republic (CZE), Denmark (DNK), England (ENG), Spain (ESP), Ireland (IRL), Latvia (LVA), Luxembourg (LUX), Malta (MLT), and Slovenia (SVN), school leadership is traditionally shared among formal leadership teams and team members. Principals, teachers, community representatives and, in some countries, governing bodies all typically constitute formal leadership teams. For most, the formal tasks deal with administration, personnel management, maintenance, and infrastructure rather than with pedagogy, monitoring, and evaluation (BarreraOsorio, Fasih, Patrinos, \& Santibanez, 2009).

In other European countries, such as Austria (AUT), Bulgaria (BGR), Italy (ITA), Lithuania (LTU), and Poland (POL), PDM occurs as a combination of formal leadership teams and informal ad-hoc groups. Ad-hoc leadership groups are created to take over specific and short-term leadership tasks, complementing the formal leadership teams. For example, in Italy these leadership roles can be defined for an entire year, and in most countries, there is no external incentive to reward participation. Participation depends upon the input of teaching and non-teaching staff, such as parents, students, and the local community, through school boards or school governors, student councils and teachers' assemblies (p. 117). In these cases, participation is more active through collaboration and negotiation of decisions. In addition, the responsibilities of PDM range from administrative or financial to specifically pedagogical or managerial. In Malta, for example, the participative members focus more on administrative and financial matters, while in Slovenia, the teaching staff creates a professional body that makes autonomous decisions about program improvement and discipline-related matters (p. 117).

In Nordic countries, such as Estonia (EST), Finland (FIN), Norway (NOR), and Sweden (SWE), schools make decisions about leadership distribution with the school leader having a key role in distributing the participative responsibilities. The participating actors are mainly the leaders of the teaching teams that implement the decisions.

One unique country, in terms of PDM, is Switzerland (CHE), where no formal distribution of school leadership and decision-making takes place.

In terms of the presence of professional community, Lomos (2017) has comparatively analyzed the presence of PC practices in all the European countries mentioned above. It was found that teachers in Bulgaria and Poland perceive significantly higher PC practices than the teachers in all other participating European countries. After Bulgaria and Poland, the group of countries with the next-highest, albeit significantly lower factor mean includes Latvia, Ireland, and Lithuania; teachers' PC perceptions in these countries do not differ significantly. The third group of countries with significantly lower PC latent scores is comprised of Slovenia, England, 
and Switzerland, followed in the middle by a larger group of countries, which includes Italy, Spain, Sweden, Norway, Finland, Estonia, and Slovakia, and followed lower by Malta, Cyprus, the Czech Republic, and Austria. Belgium (Flanders) (BFL) proves to have the lowest mean of the PC factor; it is lower than those of 19 other European countries, excluding Luxembourg and Denmark, which have PC means that do not differ significantly from that of Belgium (Flanders) (BFL).

Considering the present opportunity to study these relationships across many countries, it is important to know which decision-making actors most strongly indicate a high level of PC and whether different patterns of relationships appear for specific actors in different countries. While the TALIS 2013 report (OECD, 2016) treated the shared participative leadership concept as latent and investigated its relationship with each of the five PC dimensions separately, the present study aims to go a step further by clarifying what actors involved in decision-making prove most indicative of higher PC practices in general. Treating PC as one latent concept allows us to formulate conclusions about the effect of each actor involved in PDM on the general collaboration level within schools rather than on each separate PC dimension. To formulate such conclusions at the higher-order level of the PC latent concept, a test of measurement invariance is necessary, which will be presented later in this chapter.

Considering the exploratory nature of this study, in which the relationship between the PC concept and PDM actors will be investigated comparatively across many European countries, no specific hypotheses will be formulated. The only empirical expectation that we have across all countries, based on existing empirical evidence, is that this relationship is positive; PC and PDM actors mutually and positively influence each other.

\subsection{Method}

\subsubsection{Data and Variables}

The present study uses the European Module of the International Civic and Citizenship Education Study (ICCS 2009) performed in 23 countries. ${ }^{1}$ The ICCS 2009 evaluates the level of students' civic knowledge in eighth grade (13.5 years of age and older), while also collecting data from teachers, head teachers, and national

\footnotetext{
${ }^{1}$ The countries in the European module and included in this study are: Austria (AUT) N teachers $=949$, Belgium (Flemish) $(B F L) \mathrm{N}=1582$, Bulgaria (BGR) $\mathrm{N}=1813$, Cyprus (CYP) $\mathrm{N}=875$, the Czech Republic $(\mathrm{CZE}) \mathrm{N}=1557$, Denmark $(\mathrm{DNK})=882$, England $(\mathrm{ENG}) \mathrm{N}=1408$, Estonia (EST) $\mathrm{N}=1745$, Finland (FIN) $\mathrm{N}=2247$, Ireland (IRL) $\mathrm{N}=1810$, Italy (ITA) $\mathrm{N}=2846$, Latvia (LVA) $\mathrm{N}=1994$, Liechtenstein (LIE) $\mathrm{N}=112$, Lithuania (LTU) $\mathrm{N}=2669$, Luxembourg (LUX) $\mathrm{N}=272$, Malta (MLT) $\mathrm{N}=862$, Norway (NOR) $\mathrm{N}=482$, Poland (POL) $\mathrm{N}=2044$, Slovakia (SVK) $\mathrm{N}=1948$, Slovenia $(\mathrm{SVN}) \mathrm{N}=2698$, Spain $(\mathrm{ESP}) \mathrm{N}=1934$, Sweden $(\mathrm{SWE}) \mathrm{N}=1864$, and Switzerland (CHE) $\mathrm{N}=1416$. Greece and the Netherlands have no teacher data available.
} 
representatives. When answering the specific questions, teachers - the unit of analysis in this study - also indicated their perception of collaboration within their school, their contribution to the decision-making process, and students' influence on different decisions made within their school. In each country, 150 schools were selected for the study; from each school, one intact eighth-grade class was randomly selected and all its students surveyed. In small countries, with fewer than 150 schools, all qualifying schools were surveyed. Fifteen teachers teaching eighth grade within each school were randomly selected from all countries; in schools with fewer than 15 eighth-grade teachers, all eighth-grade teachers were selected (Schulz, Ainley, Fraillon, Kerr, \& Losito, 2010). Therefore, the ICCS unweighted data from 23 countries include more than 35,000 eighth-grade teachers, with most countries having around 1500 participating teachers (see Footnote 1 for each country's unweighted teacher sample size). The unweighted sample size varied from 112 teachers in Liechtenstein to 2846 in Italy based on the number of schools in each country and the number of selected teachers ultimately answering the survey.

In the ICCS 2009 teacher questionnaire, five items were identified as an appropriate measurement of the Professional Community latent concept in this study. Namely, the teachers were asked how many teachers in their school during the current academic year:

- Support good discipline throughout the school even with students not belonging to their own class or classes? (Collective Responsibility/CR)

- Work collaboratively with one another in devising teaching activities? (Reflective Dialogue/RD)

- Take on tasks and responsibilities in addition to teaching (tutoring, school projects, etc.)? (Deprivatisation of Practice/DP)

- Actively take part in $<$ school development/improvement activities $>^{2}$ ? (Shared sense of Purpose/SP)

- Cooperate in defining and drafting the $<$ school development plan $>$ ? (Collaborative Activity/CA)

These items, presented in the order in which they appeared in the original questionnaire, refer to teacher practices embedded into the five dimensions of PC. The five items were measured using a four-point Likert scale that went from "all or nearly all" to "none or hardly any". For the analysis, all indicators were inverted in order to interpret the high numerical values of the Likert scale as indicators of high PC participation. Around $2.5 \%$ of data were missing across all five items on average across all countries. Most countries had a low level of missing data - only 1-2\% and the largest amount of missing data was 5\%. No school or country completely lacked data. Any missing data for the five observed variables of the latent professional community concept were considered to be missing completely at random, and deletion was performed list-wise.

\footnotetext{
${ }^{2}$ The signs $<\ldots>$ mark country-specific actions, subject to country adaptation.
} 
Participative decision-making was also measured through five items indicating the extent to which different school actors contribute to the decision-making process. First, three items measure how much the teachers perceive that the following groups contribute to decision-making:

- Teachers

- School Governors

- School Counsellors

Two additional items measure how much teachers perceive students' opinions to be considered when decisions are made about the following issues:

- Teaching and learning materials

- School rules

These five items were measured on a four-point Likert scale, which ranged from "to a large extent" to "not at all". For the analysis, all indicators were inverted in order to interpret the high-numerical values of the Likert scale as an indication of high involvement. The amount of missing data varied across the five items; about $1 \%$ of data regarding teacher involvement and consideration of students' opinions was missing across all the countries. On the question of school governors' involvement, about $11 \%$ of the data were missing across all countries (the question was not applicable in Austria and Luxembourg; 10\% of missing cases were found for this question in Sweden and Switzerland). Moreover, 15\% of missing cases were found on average for the item on school counsellors' involvement (the question was not applicable in Austria, Luxembourg, and Switzerland; 10\% of missing cases were found for this question in Bulgaria, Estonia, Lithuania, and Sweden). The missing data were deleted list-wise, but the countries with more than $10 \%$ missing cases were flagged for caution in the results' graphical representations, when interpreting these countries' outcomes due to the possible self-selection by the teachers, who actually answered the questions.

\subsubsection{Analysis Method}

First, the scale reliability and the factor composition of the PC scale were tested across countries and in each individual country through both reliability analysis (Cronbach $\alpha$ for the entire scale) and factor analysis (EFA with Varimax rotation). Conditioned on the results obtained, the PC scale was built as the composite scale score, and the relationship of the scale with each item measuring PDM was investigated through correlation analysis. The level of significance was considered onetailed since positive relationships were expected. The five items measuring PDM were correlated individually with the PC scale in an attempt to disentangle what PDM aspect within schools matters most to such collaborative practices across all countries. Considering the multitude of tests applied, the Holm-Bonferroni correction indicates in this case the level of $p<.002(\alpha / 21)$ as the p-value to reject the 
null-hypothesis; the correlation bars respecting this condition are indicated with a bold pattern in the results section (see Figures).

To account for the specifics of the ICCS 2009 data, the IEA IDB Analyzer program (IEA, 2017) was used to perform all analyses, accounting for the specifics of the data through stratification, weights, and clustering adjustments, allowing us to make valid conclusions at the teacher level. These adjustments correct for the sampling strategy across countries and for the nested character of the data. Same dataspecific adjustments were applied to any analyses performed in SPSS (SPSS statistics 24$)$, such as the reliability analysis and factor analysis.

Considering that we are comparing correlation coefficients with the latent PC concept across countries, it is important to consider the equivalence of the measurement model for latent concepts in all groups. This will ensure that the associations found are in fact determined by the relationship between the concepts of interest and not by non-equivalent measurement models (Meuleman \& Billiet, 2011). Therefore, a sensitivity check was performed in this chapter. First, as a cross-validation of the results obtained, the established and presented correlation coefficients were compared with the ones obtained applying the Multiple-Group Confirmatory Factor Analysis (MGCFA) method and taking into consideration the level of measurement metric invariance of the latent PC concept across all countries. The traditional MGCFA applied here for this cross-validation indicates that relationships with latent concepts can be validly compared across groups, if the latent concept has the same factor structure in all groups (configural invariance) and if the factor loadings of the measurement model are equal in all groups (metric invariance) (e.g. Meuleman $\&$ Billiet, 2012). For this chapter, the level of model fit in terms of metric invariance for the latent PC concept will be presented; the difference in the correlations obtained with the two methods (measurement model, either considered or not considered) will be discussed in terms of their implications on the presented results and interpretation. The Mplus program (Mplus 7.31) was used to perform the sensitivity analysis presented later in this chapter with all specific data adjustments applied (weights, strata, and clustering).

Further sensitivity checks of the relationships presented in this chapter were performed to test the robustness of the results. More specifically, the correlation coefficients obtained were corrected for different teachers' demographic characteristics (age, gender, teaching experience, subject taught in the current school, and other school responsibilities besides teaching) to make sure that the relationships presented are not spurious due to such variables. Finally, checks for linear relationships were performed as well, considering that all variables in this study were measured using four-point Likert scales. 


\subsection{Results}

The results section will follow the order of the research questions, first presenting the relationships and their direction from each country while considering, which decision-making actor is indicative of high PC presence. Considering the exploratory character of this analysis, the correlation coefficients in all countries will be comparatively presented, and the most relevant results will be discussed.

The reliability analysis of the PC scale indicated satisfactory results across all countries $(\alpha=.78, \mathrm{~N}=35,897)$ and also in each individual country, with Cronbach $\alpha$ values ranging from .72 in Estonia to .87 in Luxembourg. Factor analysis indicated a one-factor structure across all countries with factor loadings higher than .68 showing also a one-factor structure in each country, excluding Estonia, where a two-factor solution, achieved by separating the first three and the last two PC items, fits better. However, the PC concept shows a satisfactory reliability level $(\alpha=.72)$ in Estonia, indicating that we can keep this country in the analysis using the one-factor approach. Liechtenstein, did not show a satisfactory reliability and factor analysis result, so it was excluded from further analyses, leaving 22 European countries. For all other countries, the evidence presented here constitutes the basis of our confidence in creating the composite score for the PC concept and to use it for the following correlation analyses.

\subsubsection{Professional Community and Participative Decision-Making}

The following three Figures present the relationships measured between PC and the perceived involvement in decision-making of the teachers, school governor, and school counsellor.

In Fig. 4.1, we see a significant and positive correlation between PC and teacher decision-making in all countries with values ranging from $r=.23$ in Denmark

\section{PC *PDM - Teachers}

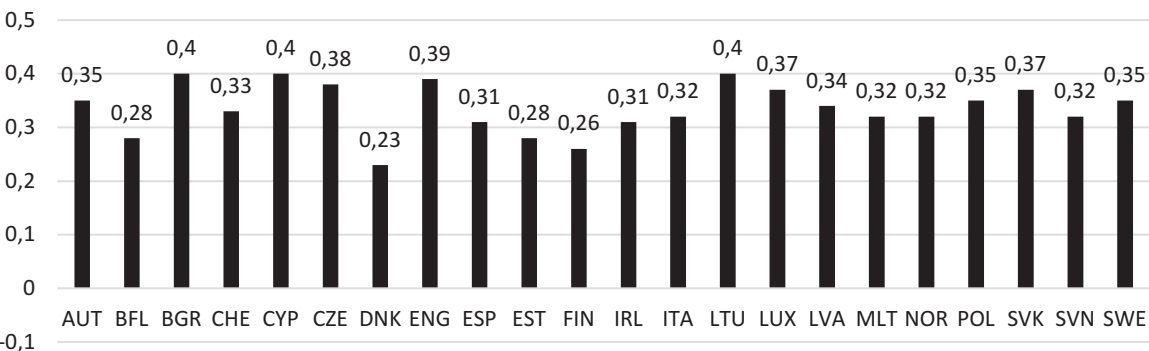

Fig. 4.1 PC and PDM - Teachers' contribution to decision-making Notes: Correlation coefficients obtained using the ICCS 2009 Teacher data, $N=35,490$. The vertical X-line indicates the correlation coefficient for each country on a scale from -1.00 to +1.00 ; the horizontal Y-line indicates the country correlation bars in alphabetical order. All relationships are significant at the one-tailed value $\mathrm{p}<.001$ 
(DNK) and $r=.26$ in Finland (FIN) to $r \approx .38$ in the Czech Republic (CZE) and England (ENG) and $r=.40$ in Bulgaria (BGR), Cyprus (CYP), and Lithuania (LTU). This outcome confirms previous empirical evidence that, when teachers are highly involved in their school's decision-making process, they also perceive higher levels of participation in PC in their school; most countries have an $r$-value higher than .30.

In England, teachers are remunerated for some distribution of leadership functions, and for that, teachers need to manage pupils' development along the curriculum (Eurydice, 2013). In Bulgaria, teachers receive additional points if they are involved in leading particular teams, and this can increase their payment, while in Cyprus, many teachers hold a Master's degree in Leadership and Administration (Eurydice, 2013). However, in Finland, the school leader may or may not establish teams of teachers with leadership roles, and these teams may be disbanded in a flexible way based on the school's interests (Eurydice, 2013).

The results are a bit different in Fig. 4.2, where we see that the relationship between PC and school governor decision-making is positive and statistically significant in all countries but with lower effect sizes, from $r \approx .10$ in Bulgaria (BGR), Spain (ESP), and Slovakia (SVK) to $r=.35$ in Poland (POL) and $r=.41$ in Lithuania (LTU). In all countries, a perception of high PC participation is not strongly related with a perception of school governors' involvement in decision-making. This finding seems to indicate that having non-teaching staff involved in decision-making and assuming a more formal leadership role does not associate strongly with a high collaborative climate, as perceived by the teachers; the strength of the relationship varies considerably between countries.

In terms of general PDM within schools at the system level, much of the choice regarding who should be involved in decisions, and to what extent, remains with the school leaders in the countries studied. In Poland, the actors leading informal leadership teams are rewarded with merit-based allowances; this is also true of Lithuania, where there are no top-level incentives for distributing decision-making, so the initiative rests with the school leader (Eurydice, 2013).

PC*PDM - School governors

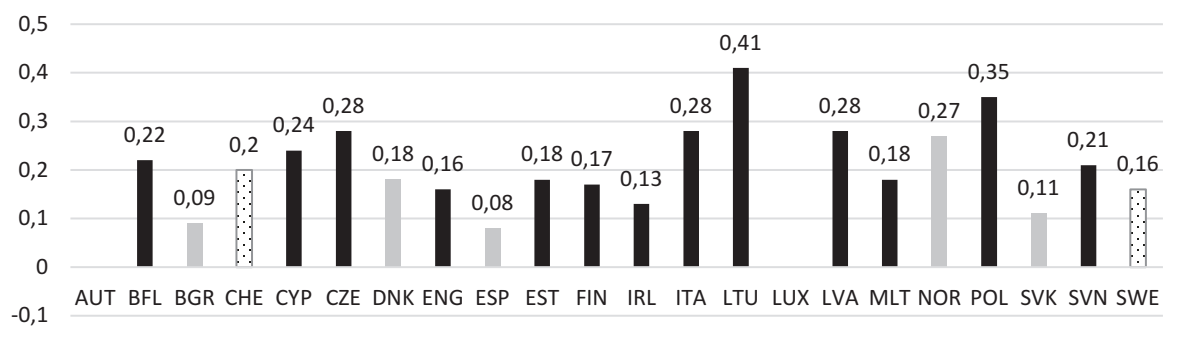

Fig. 4.2 PC and PDM - School governors' contribution to decision-making Notes: Correlation coefficients obtained using the ICCS 2009 Teacher data, $N=31,439$. The vertical X-line indicates the correlation coefficient for each country on a scale from -1.00 to +1.00 ; the horizontal Y-line indicates the country correlation bars in alphabetical order. Relationships are significant at the one-tailed value $\mathrm{p}<.001$; the lighter bars indicate a $\mathrm{p}<.05$ level; the pattern-filled bars indicate more than $10 \%$ missing answers to this PDM question; missing bars indicate that the question was not asked in these countries 
PC*PDM - School Counsellors

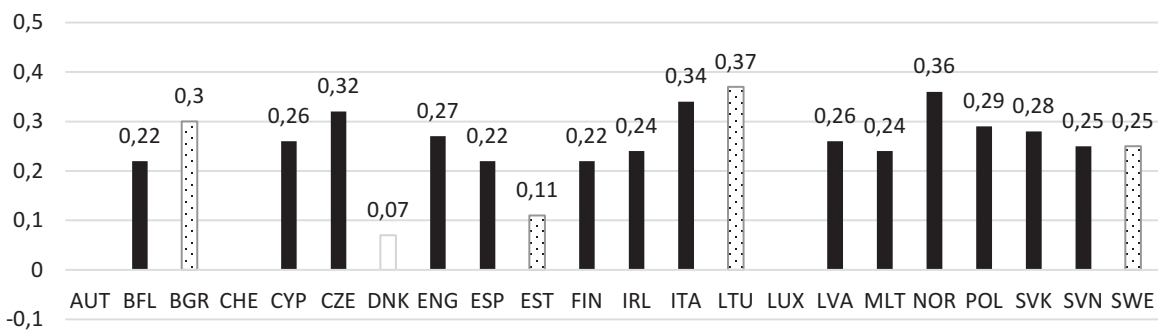

Fig. 4.3 PC and PDM - School Counsellors' contribution to decision-making

Notes: Correlation coefficients obtained using the ICCS 2009 Teacher data, $N=30,224$. The vertical X-line indicates the correlation coefficient for each country on a scale from -1.00 to +1.00 ; the horizontal Y-line indicates the country correlation bars in alphabetical order. All relationships are significant at the one-tailed value $\mathrm{p}<.001$; the empty bars indicate a non-significant relationship; the pattern-filled bars indicate more than $10 \%$ missing cases for this PDM question; missing bars indicate that the question was not asked in these countries

The same varying relationship across countries can be noted in Fig. 4.3, where the school staff perceived as involved in decision-making is the school counsellor in most countries, this is the student or educational/vocational career counsellor, psychologist, or social teacher.

One can see that in most countries, higher perceived PC is associated with higher perceived participation of school counsellors in decision-making; the majority shows a coefficient higher than $r=.22$, only Estonia (EST) is lower, and the data are not significant in Denmark (DNK). It is noteworthy that Lithuania (LTU), Poland (POL), Norway (NOR), the Czech Republic (CZE), Latvia (LVA), and Italy (ITA) are the countries with the strongest relationships between $\mathrm{PC}$ practices and the involvement of the school counsellor and, previously, the school governor in decision-making; these two relationships differ only for Bulgaria (BGR) and Slovakia (SVK) (see Figs. 4.2 and 4.3).

We also expected a positive relationship between the consideration of students' opinions in decision-making and teachers' PC participation, particularly when teachers cooperate to define the vision of the school and collaboratively take part in deciding what is best for their students. A positive and significant relationship between PC practices and the consideration of students' opinions in decisions made about teaching and learning materials can be seen in Fig. 4.4.

In Fig. 4.4, the majority of coefficients is higher than $r=.20$, with lower ones only in Austria (AUT), Switzerland (CHE), Spain (ESP), Denmark (DNK), and Malta (MLT). In Austria, there are many pilot projects supporting the redistribution of tasks among formal and informal leadership teams, especially geared towards teachers but not necessarily students; meanwhile, Switzerland was reported as having no formally shared decision-making (Eurydice, 2013).

In terms of student opinions being considered when defining school rules, Fig. 4.5 depicts its relationship with PC as positive and relatively strong in all countries; again, most correlation coefficients are higher than $r=.20$. Some of the same 


\section{PC*PDM - Student Influence - Teaching/learning materials}

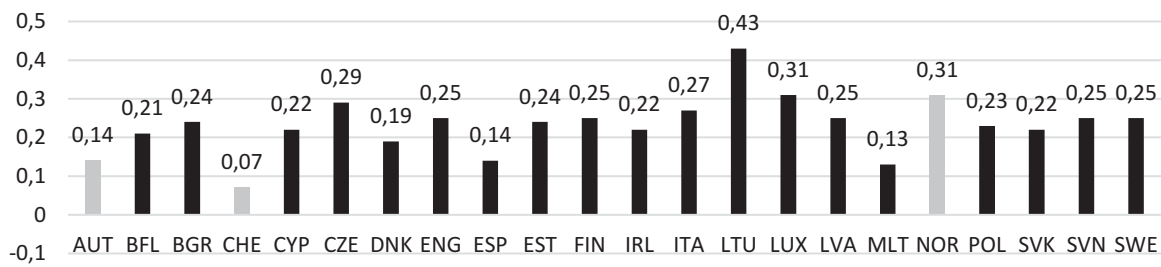

Fig. 4.4 PC and PDM - Student Opinions considered for Teaching and Learning materials Notes: Correlation coefficients obtained using the ICCS 2009 Teacher data, $N=35,105$. The vertical X-line indicates the correlation coefficient for each country on a scale from -1.00 to +1.00 ; the horizontal Y-line indicates the country correlation bars in alphabetical order. All relationships are significant at the one-tailed value $\mathrm{p}<.001$; the lighter bars indicate a $\mathrm{p}<.05$ level

PC*PDM - Student Influence - School rules

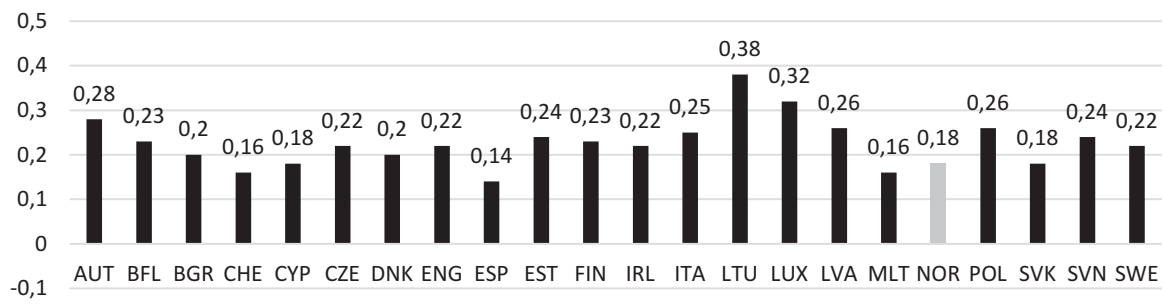

Fig. 4.5 PC and PDM - Student Opinions considered for School Rules

Notes: Correlation coefficients obtained using the ICCS 2009 Teacher data, $N=35,105$. The vertical X-line indicates the correlation coefficient for each country on a scale from -1.00 to +1.00 ; the horizontal Y-line indicates the country correlation bars in alphabetical order. All relationships are significant at the one-tailed value $\mathrm{p}<.001$; the lighter bars indicate a $\mathrm{p}<.05$ level

countries have a lower $r$ coefficient, such as Cyprus (CYP), Norway (NOR), and Slovakia (SVK), followed by even a lower $r$ coefficient of Switzerland (CHE), Spain (ESP) and Malta (MLT). In general, in all countries, teachers agree that if they perceive their school as having a high level of participation in collaboration among teachers, they also perceive a high consideration of student opinions in defining school rules, and vice versa.

\subsubsection{Sensitivity Checks}

The results presented here have been cross-validated through three sensitivity checks, all of which concern the decisions made at the beginning of the study.

The first sensitivity check addresses the importance of the measurement metric invariance level of the latent PC concept and the comparison of its relationships 
with PDM across the 22 groups. The traditional Multiple-Group Confirmatory Factor Analysis (MGCFA) indicates that relationships with latent concepts can be validly compared across groups, if the latent concept has the same factor structure in all groups (configural invariance) and if the factor loadings of the measurement model are equal in all groups (metric invariance) (e.g. Meuleman \& Billiet, 2012). In Mplus, the metric invariance model ${ }^{3}$ within MGCFA was run; it showed a satisfactory model fit after freely estimating the factor loading for Switzerland's Reflective Dialogue item, as recommended by the Model Modification Indices in JRule for Mplus (Saris, Satorra, \& Van der Veld, 2009; Van der Veld \& Saris, 2011), $(\mathrm{CFI}=.956, \mathrm{RMSEA}=.066, \Delta \mathrm{CFI}=\mathrm{I} .001 \mathrm{I}, \Delta \mathrm{RMSEA}=\mathrm{I} .001 \mathrm{I}$ compared to Full Metric Invariance, $N=35,897$ ). Taking the test for metric invariance and its adjustments into consideration, the PC latent concept was correlated with each item of the PDM concept. In all countries, the correlation coefficients obtained by considering the metric measurement invariance testing were relatively higher than those obtained without considering the measurement model. The differences between the correlation coefficients for the two approaches ranged between .01 and up to .09 points (not tested for significant differences). These small differences found in the two approaches of estimating the relationship of PC and PDM involving teachers are presented in Fig. 4.6. Considering that the significance level of the relationships did not change in the present study and taking into account the relatively large sample size in each country, we have opted for the simpler approach, which does not consider the measurement invariance model of the latent PC concept when presenting

\section{PC*PDM - Teachers}

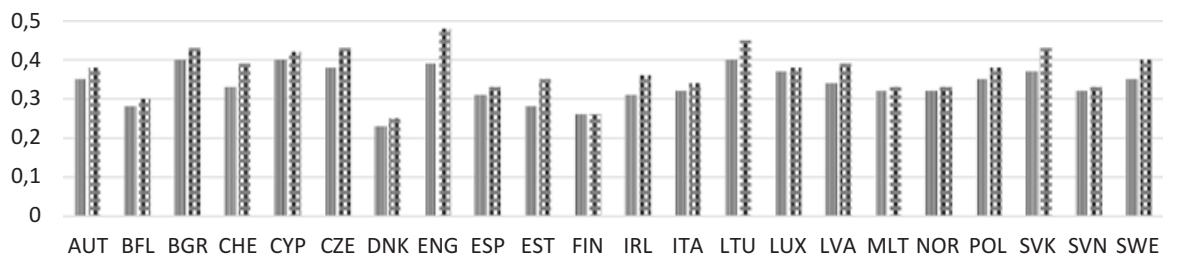

IIII Measurement model not considered

s: Measurement model considered

Fig. 4.6 PC and PDM - Teachers' contribution to decision-making within schools - comparing correlation coefficients using two approaches in terms of measurement model considered Notes: Correlation coefficients obtained using the ICCS 2009 Teacher data, $N=35,490$. The vertical X-line indicates the correlation coefficient for each country on a scale from -1.00 to +1.00 ; the horizontal Y-line indicates the country correlation bars in alphabetical order. No label values were indicated to facilitate the easy reading of the figure, but the author can provide them

\footnotetext{
${ }^{3}$ The Full Metric Invariance Model within MGCFA was run, including a total of 7 corrections in terms of allowed error term correlations between 2 items ( 2 such error term correlations in Austria, Ireland, and England, and 1 in Estonia) as required by the individual Confirmatory Factor Analysis (CFA) models, ran in each individual country, and by an a-priori satisfactory model fit for the full configural measurement invariance model. The model fit for the Full Configural Invariance Model was satisfactory $(\mathrm{CFI}=.966, \mathrm{RMSEA}=.079, \mathrm{~N}=35,897)$.
} 
the previous results. However, other studies should at least cross-validate their results by considering the measurement invariance model of latent concepts when comparing correlation coefficients; this will establish whether their relationships of interest are meaningful and supported by a satisfactory measurement metric invariance model across all groups.

The second sensitivity check addresses the relationships of interest and the risk of being spurious on demographic variables. It is possible that both the teachers' perception of PC and PDM practices are influenced by their gender, age, main subject taught (mathematics, languages, science, human sciences, or other subjects), or other roles within the school (member of the school council, assistant principal, department leader, guidance counsellor, or district representative) (e.g. Hulpia, Devos, \& Rosseel, 2009a; Wahlstrom \& Louise, 2008). To cross-validate the results, we have considered these variables alone and in different combinations in the correlation analyses performed. In all cases, the relationships stayed significant, and the size of the correlation coefficients did not change dramatically, i.e. increasing or decreasing by .05 points at most. Being a female, teaching mathematics, and being part of the school council triggered the correlation coefficient to change from .02 to .05 in some countries, such as Luxembourg (the country with the smallest sample size), but there was no change in the significance of the relationship.

The third sensitivity check addresses the decision of treating the observed items and the PC scale as continuous with all items being measured by four-point Likert scales. To cross-validate this decision, we investigated the distribution of the cases across the categories of all variables and in all countries. Across all countries, all observed variables had a lower number of responses for the lowest category ("none or hardly any" and "not at all"), with the exception of the PDM feature of students' influence on teaching and learning materials, which had a low response number for its highest category ("to a large extent"). In each case, we have merged each low- or high-response category with its closest neighboring category, creating variables with three categories each. The cross-tabulations, which were run across all countries and in each individual country, supported the expectation of a linear relationship.

\subsection{Conclusion and Discussion}

Returning to the research questions, Professional Community (PC) practices proved to be significantly and positively related to Participative Decision-Making (PDM) practices in all 22 European countries. Moreover, some actors, involved in PDM practices within schools, were more indicative of PC practices in all 22 countries, while other actors were relevant only in some countries.

All PDM features were positively and significantly related to PC practices in all countries; this is in accordance with the previous empirical evidence indicating that in schools, where such PDM structures are present, with teachers and other actors 
involved in decision-making, there is also a higher presence of PC practices (Carpenter, 2014).

However, some school actors' involvement in decision-making is more indicative of the presence of PC practices than that of other actors. More specifically, the data prove that teachers' perception of high PC correlates the strongest with high levels of teacher involvement in decision-making. Furthermore, across all countries, more than $50 \%$ of the teachers, who perceived high levels of teacher involvement in decision-making, also perceived a strong presence of teacher professional community practices. This relationship proved weaker in Denmark, however, where weak PC practices were reported by those teachers, who perceived low teacher involvement in decision-making, and also by those, who perceived moderate teacher involvement. Moreover, even those teachers, who perceived high teacher involvement in decision-making in Denmark, mostly reported only a moderate presence of teacher PC practices. This might be influenced by a low teacher-perceived presence of professional community practices on average across schools in Denmark in the 2009 ICCS data, which also applies in Flanders (Belgium) (Lomos, 2017) and Estonia.

The degree of other actors' involvement in decision-making also has a positive relationship with the presence of PC practices, but the intensity of this relationship varies more widely across countries, sometimes being consistent with specific, formal PDM practices in different national educational contexts, as presented in the theoretical section.

In terms of school governors' involvement in decision-making, the size of the correlation coefficient in Bulgaria, Spain, and Slovakia was surprisingly low. Upon closer investigation of the distribution of responses, it became apparent that in these three countries, $90 \%$ of the teachers perceive the school governor to be largely involved in decision-making; the size of the correlation coefficient is, therefore, impacted by the lack of discrimination within this variable. This distribution of answers could be expected, considering that in these countries, the PDM is formal and traditionally shared among structured leadership teams and team members. In terms of the school counselors' involvement in decision-making, it can be noted that the majority of these relationships have a correlation coefficient larger than .20; it is lower only in Estonia, and it is not statistically significant in Denmark. In Denmark, $76 \%$ of the teachers, who answered this question, indicated that the school counselor is not involved in decision-making; the analysis shows no clear relationship in this country. In Estonia, only $7 \%$ of the teachers, who answered this question, indicated that the school counselor is highly involved in decision-making; most responses indicate no involvement. To conclude, the high involvement in decisionmaking of the school governor and school counselor in each country relates positively with a high perceived participation in professional community activities; however, this conclusion is perturbed in some countries by the formal and national regulations precisely defining the role and the attributions of such formal leaderfollowers within schools.

In terms of students' involvement in student-related decision-making and the presence of professional community practices, there is not much empirical 
evidence, on which to base our expectations. From the TALIS 2013 cross-countries study (OECD, 2016), it is known that principals perceive low student participation in decision-making in countries, such as Italy, the Slovak Republic, Spain, and the Czech Republic, and a high student participation in Latvia, Poland, Estonia, Norway, England, and Bulgaria, but not much evidence is available on its relationship with teacher professional community practices. In our study, we found that the consideration of students' opinions regarding school rules is positively related to participation in teachers' PC practices; this relationship varies in strength across countries. A similar pattern of relationship can be seen between the consideration of students' opinions of teaching and learning materials, as summarized here. In both cases, student participation - in decisions about school rules and about teaching and learning materials, in Lithuania and Luxembourg have the strongest relation with PC presence, while in Spain, Malta, and Switzerland have the weakest one. The case of Luxembourg is interesting, since it has on average a predominant low perception of professional community practices in schools (Lomos, 2017) and a low perception of student influence on teaching and learning materials and school rules, based on teachers' answers in the ICCS 2009 data. This indicates that most teachers perceive their school as having either both collaborative practices and student influence on decision-making or neither of the two. High degrees of student influence on teaching and learning materials seems to be especially characteristic of schools with a supportive, collaborative, and common-vision environment. In the cases of Spain and Switzerland, the weak relationship could be determined by the fact that most teachers perceived on average a lack of students' influence on teaching and learning materials and school rules, independently of their perceived level of PC practices. The cases of Austria and Norway are unique, showing a stronger correlation of PC practices with one of the PDM features of student influence and a weaker correlation with the other. This may be influenced by the fact that one of the PDM features is present to a much larger extent than the other or is more strongly supported by the respective national educational policies.

Regarding the issue of measurement invariance when comparing relationships of latent concepts across countries, the aim is to test whether such latent concepts can be measured by the observed indicators at hand in each country (configural invariance) and, especially, to test whether they are measuring the same construct the same way across different countries (metric invariance). In this study, we found that the correlation coefficients have relatively larger values, when the metric measurement model is considered - however, with no change in the significance of the results in the different countries. For future studies, comparing relationships of latent concepts across groups implies performing and adjusting for a satisfactory measurement model fit. It is suggested that future research at least cross-validates the results obtained without invariance testing, as is the approach here. 


\subsubsection{Limitations and Future Research}

One methodological limitation is related to the design of the ICCS data; the aim of this large-scale study is to explain students' civic knowledge, attitudes, and behaviours toward the end of compulsory education. This implied that only eighth-grade teachers were randomly selected to participate in each school, reflecting, however, upon the practices of all their colleagues in their school.

A second, related limitation relates to the method by which the concepts of interest were measured by the ICCS teacher questionnaire. We were only able to capture who participated in decision-making and to what extent, but not exactly what the tasks and roles of these actors were. Hulpia et al. (2009a) identified different roles and tasks of followers when assuming leadership roles, which have an important impact on the measured outcomes. Moreover, Harris (2009) pointed out that when too many leaders are present, this could negatively affect team outcomes due to inconsistencies in responsibilities and roles or conflicting priorities and objectives. However, we are not able to account for these factors here. We only focused on the actors involved in decision-making and neither on the type of relationship nor on the quality of outcomes determined by this relationship. Kennedy, Deuel, Nelson, and Slavit (2011) also identified several important attributes of participative leadership that would support the development of strong school communities and teacher collaboration, which we were not able to assess in order to understand what could determine the positive association found.

Following the same line of reasoning, the five dimensions of the PC concept have been measured with only one item each, while some previous studies used three or more items per dimension. Moreover, some of the items are proxies of the dimensions of interest, such as the item measuring deprivatisation of practice. This dimension is measured by teachers' willingness to take on additional tasks besides teaching, such as tutoring or school projects, which could require some deprivatisation of individual practice.

Another limitation of the present study is determined by the decision of considering the PC and PDM practices as teacher practices, expressed through teacher perceptions of school practices. The unit of analysis here is the teacher, and the same-school dependency of their answers has been corrected when obtaining the results. The interest of the present study is to grasp the relationship at the teacher level, but future research could consider these characteristics as school-based and investigate their impact at the school level as well, using a multilevel data analysis approach. The work of Scherer and Gustafsson (2015) could be applicable, especially when building more complex multilevel structural equation models with cross-level interactions; new research could consider PC and PDM as attributes of teachers or/and of schools, depending on the conceptualization and the theoretical relationships of interest. When considering the concepts as school characteristics, it would be relevant to account for the possible effects of other school characteristics, such as size, organization, complexity of environment, structural arrangement, and level of school performance (Hulpia, Devos, \& Rosseel, 2009b; Scott, 1995 in 
Spillane et al., 2004) and possibly social composition or community context. Louis, Mayrowetz, Smiley, and Murphy (2009) have also pointed out that the size of the school and the number of departments within a secondary school can affect the creation and quality of the relationship investigated. Such a comprehensive approach would require multilevel data analysis, which would also provide the within- and between-levels of variance.

Future studies could also investigate whether the measured relationships change over time at the macro-level by using the cross-sectional ICCS data measured in 1999, 2009, and 2016 for the countries available. However, to grasp how these relationships change over time at micro-level, longitudinal teacher data would be necessary. Such longitudinal teacher data would also allow researchers to dive into the causal relationships and understand how these concepts influence each other over time, thus creating paths to improve learning (Hallinger \& Heck, 1996; Pitner, 1988).

Future research could focus on many aspects of the cross-country relationships identified. One interesting approach could be to explain why these relationships differ in intensity across countries. Future studies could try to classify the countries by European region; by the distinction made by Hofstede's classification (2001) between 'collectivist' and 'individualist' cultures (with Ning, Lee, and Lee (2015) arguing that knowledge-sharing and collaboration could be higher in collectivist countries); by level of students' success expressed comparatively across countries in large-scale assessment studies' results (e.g. the Programme for International Student Assessment (PISA); or others); by the type of educational system according to the degree of participative and collaborative practices among educational actors or the amount of investment in professional collaborative practices (Eurydice, 2013; Muijs, West, \& Ainscow, 2010); by the within-country variation (data permitting), keeping in mind that larger European countries, such as Italy or Spain, might have different PDM policies between regions; and by other criteria concerning countries and educational systems. Understanding why countries align or differ in the relationships between school capacities and processes would help advance school effectiveness literature and its empirical explanations.

\section{References}

Barrera-Osorio, F., Fasih, T., Patrinos, H. A., \& Santibanez, L. (2009). Decentralized decision-making in schools. In The theory and evidence on school-based management. Washington, DC: The World Bank. Retrieved from World Bank http:// siteresources.worldbank.org/EDUCATION/Resources/278200-1099079877269/5476641099079934475/547667-1145313948551/Decentralized_decision_making_schools.pdf

Billiet, J. (2003). Cross-cultural equivalence with structural equation modelling. In J. Harkness, F. Van de Vijver, \& P. Mohler (Eds.), Cross-cultural survey methods (pp. 247-265). New York, NY: Wiley.

Boeve-de Pauw, J., \& van Petegem, P. (2012). Cultural differences in the environmental worldview of children. International Electronic Journal of Environmental Education, 2(1), 1-11.

Carpenter, D. (2014). School culture and leadership of professional learning communities. International Journal of Educational Management, 29(5), 682-694. 
Conway, J. A. (1984). The myth, mystery, and mastery of participative decision making in education. Educational Administration Quarterly, 20(3), 11-40.

Creemers, B. (1994). The history, value and purpose of school effectiveness studies. In D. Reynolds, B. P. M. Creemers, et al. (Eds.), Advances in school effectiveness research and practice (pp. 9-23). Pergamon, Turkey: Elsevier Ltd.

Earley, P., \& Weindling, D. (2010). Understanding school leadership, SAGE Publications: ProQuest eBook Central.

Eurydice. (2013). Key data on teachers and school leaders in Europe. Eurydice Report, Retrieved from EU Publications https://publications.europa.eu/en/publication-detail/-/ publication/17ad39ad-dcad-4155-8650-5c63922f8894/language-en

Hallinger, P., \& Heck, R. H. (1996). Reassessing the principal's role in school effectiveness: A review of the empirical research. Educational Administration Quarterly, 32(1), 27-31.

Hargreaves, A., \& Fink, D. (2009). Distributed leadership: Democracy or delivery? In A. Harris (Ed.), Distributed leadership - Different perspectives (Studies in educational leadership series, 7) (pp. 181-196). Dordrecht, The Netherlands: Springer.

Harris, A. (2009). Distributed Leadership: What we know. In A. Harris (Ed.), Distributed leadership - Different perspectives (Studies in educational leadership series, 7) (pp. 101-120). Dordrecht, The Netherlands: Springer.

Hofman, R. H., Hofman, W. H. A., \& Gray, J. M. (2015). Three conjectures about school effectiveness: An exploratory study. Cogent Education, 2(1), 1-13.

Hofstede, G. (2001). Culture's consequences: Comparing values, behaviors, institutions, and organizations across nations (2nd ed.). Thousand Oaks, CA: Sage.

Hulpia, H., Devos, G., \& Rosseel, Y. (2009a). Development and validation of scores on the distributed leadership inventory. Educational and Psychological Measurement, 69(6), 1013-1034.

Hulpia, H., Devos, G., \& Rosseel, Y. (2009b). The relationship between the perception of distributed leadership in secondary schools and teachers' and teacher leaders' job satisfaction and organizational commitment. School Effectiveness and School Improvement, 20(3), 291-317.

IEA. (2017). Help Manual for the IEA IDB Analyzer (Version 4.0). Hamburg, Germany. Retrieved from IEA: www.iea.nl/data.html

Janson, C., Stone, C., \& Clark, M. A. (2009). Stretching leadership: A distributed perspective for school counsellor leaders. Professional School Counselling, 13(2), 98-106.

Kennedy, A., Deuel, A., Nelson, T. H., \& Slavit, D. (2011). Requiring collaboration or distributing leadership? Kappan, 92(8), 20-24.

Kruse, S. D., Louis, K. S., \& Bryk, A. S. (1995). An emerging framework for analyzing schoolbased professional community. In K. S. Louis, S. D. Kruse, \& Associates (Eds.), Professionalism and community: Perspectives on reforming urban schools (pp. 23-44). Thousand Oaks, CA: Corwin Press.

Lambert, L. (2003). Leadership capacity for lasting school improvement. Alexandria, VA: Association for Supervision and Curriculum Development.

Little, J. W. (1990). The persistence of privacy: Autonomy and initiative in teachers' professional relations. Teachers College Record, 91(4), 509-536.

Logan, J. P. (1992). School-based decision-making: First-year perceptions of Kentucky teachers, principals, and counselors. Retrieved from EDRS/ERIC Clearinghouse: https://catalogue.nla. gov.au/Record/5561935

Lomos, C. (2017). To what extent do teachers in European countries differ in their professional community practices? School Effectiveness and School Improvement, 28(2), 276-291.

Lomos, C., Hofman, R. H., \& Bosker, R. J. (2012). The concept of professional community and its relationship with student performance. In S.G. Huber \& F. Algrimm (Eds.), Kooperation: Aktuelle Forschung zur Kooperation in und zwischen Schulen sowie mit anderen Partnern (pp. 51-68). Berlin: Waxmann.

Louis, K. S., Dretzke, B., \& Wahlstrom, K. (2010). How does leadership affect student achievement? Results from a national US survey. School Effectiveness and School Improvement, 21(3), 315-336. 
Louis, K. S., \& Kruse, S. D. (1995). Professionalism and community: Perspectives on reform in urban schools. Thousand Oaks, CA: Corwin Press.

Louis, K. S., \& Marks, H. M. (1998). Does professional community affect the classroom? Teachers' work and student experiences in restructuring schools. American Journal of Education, 106, 532-575.

Louis, K. S., Mayrowetz, D., Smiley, M., \& Murphy, J. (2009). The role of sense-making and trust in developing distributed leadership. In A. Harris (Ed.), Distributed leadership - Different perspectives (Studies in educational leadership series, 7) (pp. 157-180). Dordrecht, The Netherlands: Springer.

Melcher, A. J. (1976). Participation: A critical review of research findings. Human Resource Management, 15, 12-21.

Meuleman, B., \& Billiet, J. (2011). Religious involvement: Its relation to values and social attitudes. In E. Davidov, P. Schmidt, \& J. Billiet (Eds.), Cross-cultural analysis: Methods and applications (pp. 173-206). New York, NY: Routledge, Taylor \& Francis Group.

Meuleman, B., \& Billiet, J. (2012). Measuring attitudes toward immigration in Europe: The crosscultural validity of the ESS immigration scales. Research and Methods, 21(1), 5-29.

Morrisey, M. (2000). Professional learning communities: An ongoing exploration. Austin, TX: Southwest Educational Development Laboratory.

Muijs, D., West, M., \& Ainscow, M. (2010). Why network? Theoretical perspectives on networking. School Effectiveness and School Improvement, 21, 5-26.

Ning, H. K., Lee, D., \& Lee, W. O. (2015). Relationships between teacher value orientations, collegiality, and collaboration in school professional learning communities. Social Psychology of Education, 18, 337-354.

OECD. (2016). School leadership for developing professional learning communities. Teaching in Focus 15(September), 1-4. Retrieved from OECD.ORG - Education Indicators in Focus http:// www.oecd.org/edu/skills-beyond-school/educationindicatorsinfocus.htm

Pitner, N. J. (1988). The study of administrator effects and effectiveness. In N. Boyan (Ed.), Handbook of research in educational administration (pp. 99-122). New York, NY: Longman.

Purkey, S. C., \& Smith, M. S. (1983). Effective schools: A review. Elementary School Journal, 83(4), 427-452.

Rosenholtz, S. J. (1989). Teachers' workplace: The social organization of schools. New York, NY: Longman.

Saris, W. E., Satorra, A., \& Van der Veld, W. M. (2009). Testing structural equation models or detection of misspecifications? Structural Equation Modeling: A Multidisciplinary Journal, $16,561-582$.

Scherer, R., \& Gustafsson, J. E. (2015). Student assessment of teaching as a source of information about aspects of teaching quality in multiple subject domains: An application of multilevel bifactor structural equation modeling. Frontiers in Psychology, 6, 1550.

Schulz, W., Ainley, J., Fraillon, J., Kerr, D., \& Losito, B. (2010). ICCS 2009 international report: Civic knowledge, attitudes, and engagement among lower-secondary school students in 38 countries. Amsterdam, The Netherlands: IEA. Retrieved from IEA: https://www.iea.nl/fileadmin/user_upload/Publications/Electronic_versions/ICCS_2009_International_Report.pdf

Smylie, M. A., Lazarus, V., \& Brownlee-Conyers, J. (1996). Instructional outcomes of schoolbased participative decision-making. Educational Evaluation and Policy Analysis, 18(3), 181-198.

Spillane, J. P., Halverson, R., \& Diamond, J. B. (2004). Towards a theory of leadership practice: A distributed perspective. Journal of Curriculum Studies, 36(1), 3-34.

Stoll, L., \& Louis, K. S. (2007). Professional learning communities: Elaborating new approaches. In L. Stoll \& K. S. Louis (Eds.), Professional learning communities: Divergence, depth and dilemmas (pp. 1-13). Maidenhead, UK: Open University Press.

Toole, J. C., \& Louis, K. S. (2002). The role of professional learning communities in international education. In K. Leithwood \& P. Hallinger (Eds.), Second international handbook of educational leadership and administration (pp. 245-279). Dordrecht, The Netherlands: Kluwer. 
Van der Veld, W. M., \& Saris, W. E. (2011). Causes of generalized social trust. In E. Davidov, P. Schmidt, \& J. Billiet (Eds.), Cross-cultural analysis: Methods and applications (pp. 207-248). New York, NY: Routledge, Taylor \& Francis Group.

Wahlstrom, K. L., \& Louise, K. S. (2008). How teachers experience principal leadership: The roles of professional community, trust, efficacy, and shared leadership. Educational Administration Quarterly, 44(4), 458-495.

Wingfield, R. J., Reese, R. F., \& West-Olantunji, C. A. (2010). Counselors as leaders in schools. Florida Journal of Educational Administration and Policy, 4(1), 114-130.

Wohlstetter, P., Smyer, R., \& Mohrman, S. A. (1994). New boundaries for school-based management. Educational Evaluation and Policy Analysis, 16, 268-286.

Open Access This chapter is licensed under the terms of the Creative Commons Attribution 4.0 International License (http://creativecommons.org/licenses/by/4.0/), which permits use, sharing, adaptation, distribution and reproduction in any medium or format, as long as you give appropriate credit to the original author(s) and the source, provide a link to the Creative Commons license and indicate if changes were made.

The images or other third party material in this chapter are included in the chapter's Creative Commons license, unless indicated otherwise in a credit line to the material. If material is not included in the chapter's Creative Commons license and your intended use is not permitted by statutory regulation or exceeds the permitted use, you will need to obtain permission directly from the copyright holder. 